[RADIOCARBON, Vol 22, No. 3, 1980, P 962-963]

\title{
NEW NATIONAL BUREAU OF STANDARDS CONTEMPORARY CARBON-14 STANDARDS*
}

\author{
L M CAVALLO and W B MANN
}

National Bureau of Standards, Washington, DC, 20234

In 1957 the National Bureau of Standards (NBS) agreed, at the request of James $\mathrm{R}$ Arnold, to store and distribute an oxalic acid contemporary carbon-14 standard. In 1978 stocks of this standard were practically gone. We approached Chas Pfizer and Company, Inc, which had provided the original 1000 pounds of oxalic acid to Dr Arnold to see if they could provide another one-batch lot of 1000 pounds of oxalic acid to replace the old standard. This they did generously, at no cost to NBS. The oxalic acid was prepared by fermentation of French beet molasses from the 1977 spring, summer, and autumn harvest using Aspergillus niger var. The acid was separated from the broth as the insoluble calcium salt and reconverted to free acid using sulfuric acid. The free acid was then crystallized, redissolved, filtered, recrystallized, and dried.

Prior to receipt of the oxalic acid at NBS, arrangements were made to distribute half-pound samples of the old and new standards to leading domestic and international laboratories for intercomparative massspectrometric and activity-concentration measurements. The response was again generous and 16 laboratories offered to make such measurements. A slight problem arose, however, on how to prepare representative samples of the new standard from 198 five-pound jars of the material. This was solved by transferring one teaspoonful of oxalic acid from each of the 198 jars into each of a number of bottles for distribution to the participating laboratories. In order to test the homogeneity of the batch, a second half-pound bottle, containing oxalic acid all taken from one five-pound jar chosen at random, was sent to each laboratory for measurement.

Results have now been received from 12 of the participating laboratories. It is expected, however, that results that can be included in the final analysis may be forthcoming from four other laboratories. In the meantime, this note gives the average ${ }^{14} \mathrm{C}$ radioactivity-concentration ratio of the new-to-old oxalic acid obtained from the data now available.

Of the 12 laboratories submitting results, 4 were for the carbon-13 abundances only, while the other 8 laboratories submitted both activityconcentration ratios and in-house mass-spectrometric measurements of samples prepared from both the old and the new oxalic acid standards. Four of the counting laboratories also sent samples of carbon dioxide to W G Mook for mass-spectrometric analysis. By and large, there appears to be some systematic bias of the mass-spectrometric $\delta^{13} \mathrm{C}$ values (relative to PDB) between the different mass-spectrometers, but the differences in the $\delta^{13} \mathrm{C}$ values between the old and the more abundant new standard

* Contribution of the National Bureau of Standards, not subject to copyright 
$\left(\Delta\left(\delta^{13} \mathrm{C}\right)\right)$ seem to be fairly consistent and the average value of $\Delta\left(\delta^{13} \mathrm{C}\right)$, including Professor Mook's $\delta^{13} \mathrm{C}$ values, is equal to $(1.51 \pm 0.17) \%$ where the uncertainty is one estimated standard deviation.

Of the results submitted by the eight laboratories, one value for the activity-concentration ratio of the new to the old standard was clearly out of line and has been rejected. Pending further clarification, a further result was temporarily rejected because of discordant $\delta^{13} \mathrm{C}$ values.

From the results reported by the remaining six laboratories, based only on their own data, the weighted average ratio of radioactivity concentrations (for $\delta^{13} \mathrm{C}=-19 \%$, relative to $\mathrm{PDB}$, for both standards) is equal to $1.2894 \pm 0.0005$, where the uncertainty is one weighted estimate of the standard deviation. The corresponding unweighted average value of the ratio of activity concentrations is $1.2888 \pm 0.0027$ where the uncertainty is one standard deviation.

The carbon-13 abundance is higher in the new standard to such an extent that $\Delta\left(\delta^{13} \mathrm{C}\right)$, in parts per thousand, is equal to $1.51 \pm 0.17$. Thus, the actual ratio of carbon-14 activities per unit mass of each standard will be greater by a factor of 1.0030 (equal to $1+2 \delta^{13} \mathrm{C}$ ). The activity-concentration ratio based on the difference in isotopic fractionation between the two standards is therefore $1.2927 \pm 0.0027$ calculated on unweighted data, the uncertainty being the standard deviation. The ratio weighted according to the stated random uncertainties given by each participant is $1.2933 \pm 0.0004$.

When we have received all the results that may still be forthcoming, we will submit a more detailed analysis, together with individual laboratory results, to Radiocarbon for publication. In the meantime, consideration is being given to distributing one-half-pound samples as research material to laboratories that order them.

We are very grateful to Minze Stuiver and P M Grootes for many helpful discussions and for having made a preliminary analysis of the submitted data. 